\title{
ABJEÇÃO AUTOBIOGRÁFICA: FRANCIS XAVIER ENDERBY COMO DEJETO DE ANTHONY BURGESS
}

\author{
Amaury Garcia dos Santos Neto* \\ Pontifícia Universidade Católica do Rio de Janeiro
}

\begin{abstract}
Resumo: Considerando a possibilidade de interseção entre textos pertencentes ao espaço biográfico de um dado indivíduo (noção primeiramente sugerida por Lejeune e expandida por Arfuch), assim como a potencialidade gerada por tais interseções em construir novas facetas ou subjetividades alternativas acerca de tal indivíduo, proponho analisar a personagem Francis Xavier Enderby, protagonista do romance autobiográfico Enderby por dentro, do escritor inglês Anthony Burgess, como sua subjetividade alternativa. Ademais, proponho uma leitura baseada em questões relacionadas à noção de abjeção. Entendo que a escrita de ficções autobiográficas possa ser um exercício através do qual um dado autor tente reconhecer lados de sua subjetividade que não gostaria de assumir como parte integrante de seu eu, ou uma tentativa de assenhorear-se de experiências desagradáveis ou traumáticas pelas quais passou, ou seja, uma busca por lidar com seu lado abjeto. Seguindo tal premissa, apresento comparações entre a auto-imagem construída por Anthony Burgess em sua autobiografia e a personagem ficcional acima referida.
\end{abstract}

Palavras-chave: Espaço biográfico. Romance autobiográfico. Subjetividades alternativas. Abjeção.

\section{Introdução}

Neste artigo, abordarei o romance Enderby por dentro do escritor inglês Anthony Burgess, propondo uma leitura que busque por elementos autobiográficos do autor em tal narrativa. Nesta obra, o romancista aborda alguns temas autobiográficos que lhe causaram enorme desconforto. Um dos principais aspectos aludidos no romance acima referido é a relação que Burgess mantivera com sua fé religiosa, o catolicismo. Apesar de ter renegado tal

\footnotetext{
* Mestre em Literaturas de Língua Inglesa pela UERJ. Doutorando em Literatura, Cultura e Contemporaneidade pela PUC-Rio. Realiza pesquisa sobre autobiografia, romances autobiográficos e afetos causados por leituras dialógicas entre tais discursos. Este artigo foi escrito com auxílio de bolsa do CNPq.
} 
fé em sua juventude, Burgess sempre se manteve próximo a seus ideais, e sempre defendeu o catolicismo quando confrontado com outras propostas metafísicas. Além disso, o romancista demonstrou, em inúmeras entrevistas, forte sentimento de culpa por sua apostasia. Seu constante retorno a tal tema, e o fato de Burgess abordá-lo em Enderby por dentro, me levam à seguinte indagação: poderia o protagonista do referido romance, o poeta Francis Xavier Enderby, ser lido como dejeto autobiográfico de Anthony Burgess?

Ao propor a ideia de dejeto autobiográfico, penso a escrita autobiográfica como um processo duplo, que, a princípio, poderia ser visto como paradoxal. Para os propósitos deste artigo, concebo esse processo como uma busca de assimilação de experiências desagradáveis por parte do autobiógrafo, num intuito de assenhorear-se de tais experiências. Simultaneamente, tal processo seria uma tentativa de se desvencilhar dessas vivências, de purgar traços de uma história de vida ou de uma subjetividade que gerassem repulsa ao autobiógrafo. É justamente esse duplo movimento de reconhecimento e abjeção que seria entendido, em primeira instância, como paradoxal.

Ao pensar na escrita ficcional de Anthony Burgess, a ideia de dejeto autobiográfico se torna especialmente interessante. $\mathrm{O}$ romancista inglês entendia o ato de escrever como uma experiência catártica. Numa entrevista, quando questionado sobre a recontextualização do ataque sofrido por sua primeira esposa no romance A Laranja Mecânica, Burgess argumentou o seguinte:

\begin{abstract}
Acredito que seja o trabalho do artista, especialmente do romancista, o de usar eventos como este, de sua própria vida, ou das vidas de seus próximos, e purgá-los, catartizar a dor, a angústia, numa obra de arte. É um dos objetivos da arte; creio ter sido D. H. Lawrence que disse "nós projetamos nossas moléstias em obras de arte"1. (BURGESS, 03 de abril de 2011)
\end{abstract}

Essa noção, tipicamente burgessiana, de purgação de sentimentos através da arte foi explorada pelo romancista em outra entrevista, em meados dos anos 70, no talk-show de Dick Cavett. Naquela ocasião, Burgess disse compreender o ato de escrever como algo extremamente insalubre. Para o romancista, escrever levaria o indivíduo a se sentir constipado, como também a ter crises de diarreia, não ao mesmo tempo, obviamente ${ }^{2}$. Sua insistência nessa comparação entre o escrever e o purgar faz com que eu creia que Burgess visse sua prática de romancista como canal para purgação de suas mazelas. Ao considerar os romances autobiográficos do escritor, a constipação talvez signifique o momento em que

\footnotetext{
1 Tradução livre. Todas as citações do trabalho, se traduzidas para a língua portuguesa, e não indicadas na bibliografia, são de minha autoria.

2 A cena em que Burgess faz esta declaração pode ser vista na rede, no seguinte endereço: http://www.youtube.com/watch?v=_ps_q9ycuDw - Acesso em: 29 maio 2011.
} 
Burgess digere certos acontecimentos de seu passado, ou seja, este é o momento em que ele reflete sobre sua experiência. Já a necessidade de se sentar ao vaso sanitário numa crise de diarreia significaria excretar aquilo que não é aproveitado, o indesejável, isto é, seu lado abjeto. A metáfora da excreção significaria a impressão de pensamentos ou sentimentos no papel, o ato de escrever, o narrativizar.

Esta metáfora está presente de forma ainda mais impactante e concreta em Enderby por dentro. Ao ser inspirado pela musa, Enderby tem a necessidade de se dirigir ao banheiro, sentar no vaso sanitário, para então escrever. O que teria motivado Burgess a descrever o processo de composição poética de sua personagem de maneira tão inusitada? Teria ele feito isso pois escrevia sobre aspectos autobiográficos desagradáveis? Buscava Burgess se purgar de suas mazelas através de Enderby? Sabendo que o romance em questão é autobiográfico, e tendo em mente a noção burgessiana de purgação através da escrita, abordarei a questão anteriormente levantada: seria Francis Xavier Enderby um dejeto autobiográfico de Anthony Burgess?

Para tal, tocarei em questões relativas à teoria do trauma e ao conceito de abjeção. Além disso, visto que a obra principal a ser tratada é um romance, discutirei as imbricações entre o discurso autobiográfico e o discurso ficcional, como também os possíveis deslocamentos dos limites desses discursos. Proponho, então, dividir o artigo em mais três seções. Na primeira seção, cobrirei brevemente questões teóricas que concernem os deslocamentos de limites do discurso autobiográfico e do discurso ficcional, assim como a possibilidade de interseções entre ambos. Na segunda seção, abordarei a questão da dor e do trauma, tendo como base o texto "Além do Princípio do Prazer", de Sigmund Freud, para então a relacionar à escrita autobiográfica. Também cobrirei a noção de abjeção, buscando relacioná-la à ficcionalização da bios. Num terceiro momento, descreverei os temas centrais de Enderby por dentro, buscando demonstrar, primeiramente, porque o romance pode ser lido por um viés que privilegie a recepção de aspectos autobiográficos. Também articularei os aspectos teóricos cobertos no corpo do trabalho a questões levantadas por minha abordagem do romance, a fim de chegar a uma resposta à indagação acima formulada. Minha premissa é que a ficção autobiográfica possa ser lida como ato de abjeção, i.e. como a busca de um autor por extirpar-se de suas experiências indesejáveis, o que me levaria a conceber a hipótese de que o protagonista Francis Xavier Enderby possa ser lido como dejeto autobiográfico de Anthony Burgess. Lembro ao leitor que o aspecto autobiográfico que enfocarei diz respeito à apostasia do escritor. 


\section{O espaço biográfico}

Em seu texto seminal "O pacto autobiográfico", Philippe Lejeune propõe definições para a autobiografia como gênero, para depois discutir, mesmo que de forma breve, outros tipos de escritos que tangenciam tal gênero. Depois de explicar sua ideia de "pacto autobiográfico", que, grosso modo, seria um pacto assumido entre escritor e leitor quando da produção e recepção de uma autobiografia (LEJEUNE, 2008, p. 44-47), o teórico propõe a ideia de "espaço autobiográfico". Este seria um espaço de comunicação entre textos concebidos como autobiografias e textos ficcionais que tangenciam aspectos relacionados à bios de um determinado indivíduo (LEJEUNE, 2008, p. 43). Num dado momento, Lejeune parece conceber romance autobiográfico e autobiografia como escritos que se completam um ao outro. Ele afirma que o romance autobiográfico traria a complexidade e a ambiguidade que faltam à autobiografia, ao passo que a autobiografia traria a exatidão que falta ao romance autobiográfico. Ao ler os dois discursos em conjunto, o leitor teria a sensação da criação do que Lejeune denomina relevo, que proporcionaria maior amplitude ou maior densidade ao relato da referida bios ou subjetividade (LEJEUNE, 2008, p. 43). O cruzamento de elementos da autobiografia com elementos do romance autobiográfico funcionaria como um dispositivo ou fenômeno em que escritos ficcionais adicionariam novas camadas de realidade à bios ou à subjetividade relatada, reforçando o que é descrito na autobiografia, e representando a realidade da mesma sob novas e diferentes perspectivas. $\mathrm{O}$ teórico reconhece que tal ideia não concebe a autobiografia como melhor que o romance autobiográfico, ou vice-versa, mas que os dois devem ser lidos “um em relação ${ }^{3}$ ao outro" (LEJEUNE, 2008, p. 43).

Leonor Arfuch explora as possibilidades oferecidas pela noção de relevo em seu livro O espaço biográfico: dilemas da subjetividade contemporânea. O que Arfuch denomina como espaço biográfico seria um conjunto de discursos, de tipos variados, cujos conteúdos são a bios de um determinado indivíduo (ARFUCH, 2010, p. 21-22). Neste conjunto, estariam agrupados não apenas autobiografias, mas vários outros tipos de escritas-de-si ${ }^{4}$, textos estes que teriam a potencialidade de projetar diferentes imagens de tal indivíduo. Arfuch se centra em construções autobiográficas feitas através de gêneros mais modernos, como a entrevista, por exemplo. Mas, o que me chama a atenção na obra da autora é a possibilidade que se abre

\footnotetext{
${ }^{3}$ Grifos do próprio autor.

${ }^{4} \mathrm{O}$ termo "escritas-de-si" funciona como termo geral para designar todo o tipo de escrita autobiográfica, incluindo autobiografias, diários, testemunhos, romances autobiográficos, autoficções, autoetnografias, entre outros.
} 
para a interseção dos textos contidos no espaço biográfico. Ao articular esses textos, o pesquisador poderia se centrar em facetas já atribuídas a um dado indivíduo, conferindo maior relevo às mesmas, ou enfocar facetas que tenham sido descritas em relatos autobiográficos, mas que não tenham recebido espaço ou atenção privilegiados. Desta forma, o romance autobiográfico traria a potencialidade de reconstituir aspectos da subjetividade de um autor que o mesmo não tivesse privilegiado em outros de seus escritos autobiográficos, o que capacitaria o pesquisador a construir novas imagens que representassem tal indivíduo.

Mas, não seria um equívoco procurar reconstituir a subjetividade ou a bios de um autor a partir de escritos ficcionais? O que um escritor revelaria num romance que já não tivesse feito em sua própria autobiografia? Helmut Galle, em "Elementos para uma nova abordagem da escritura autobiográfica", afirma que o romance autobiográfico dá ao autor a possibilidade de entrar num jogo que admite outra subjetividade, diferente de sua subjetividade oficial, o que o confere o poder de "expor um lado oculto para que seja reconhecido sem obrigação de responsabilizar-se" (GALLE, 2006, p. 80-81). Esta liberdade em não assumir a responsabilidade sobre o que é escrito faz com que eu conceba o romance autobiográfico como texto de extrema importância para desvendar ou compreender certos aspectos sobre a vida de um autor. Ao escrever sobre pessoas reais, o autobiógrafo tem suas mãos atadas, ele não tem total liberdade para dizer o que pensa, já que pode sofrer represálias. Num romance isto geralmente não constitui problema, já que o autor nos apresenta, em princípio, personagens e eventos imaginários.

Outro problema que o autobiógrafo pode enfrentar é sua própria limitação em lidar com alguns dados indesejáveis de sua vida. Sua dificuldade em aceitar o fato de ter vivenciado certos eventos poderia comprometer a descrição de tais dados. Isso pode ocorrer por várias razões, dentre elas a vergonha em admitir tal vivência, ou até mesmo por tais eventos se configurarem como traumáticos. A ficcionalização de seu próprio passado, combinada com a narração em terceira pessoa, poderia funcionar como estratégia para aumentar a distância entre o autor e aquilo que é narrado sobre sua vida, lhe conferindo, assim, maior liberdade de seus medos ou de sua vergonha. O discurso ficcional, então, auxiliaria o autor na transcrição desses dados indesejáveis, já que, em princípio, o romancista escreve sobre pessoas e situações alheias, que são originadas de sua imaginação, e, portanto, se encontram distantes.

A liberdade proporcionada pela ficcionalização de seu próprio passado traria ao indivíduo a possibilidade de revisitar momentos indesejáveis de sua vida, por um viés 
distanciado, lhe conferindo a chance de melhor compreender e assimilar tais momentos. Tal noção se assemelha ao processo psicanalítico que auxilia um indivíduo traumatizado a assimilar seus traumas, e aprender a conviver com eles. Neste processo, o indivíduo também visitaria momentos cruciais de sua vida, em que algum trauma tivesse se estabelecido. Porém, ao revisitá-los, o individuo estaria psicologicamente preparado para reviver a experiência traumática, o que o permitiria a assenhorear-se da mesma. Este é um dos aspectos semelhantes entre a escrita ficcional autobiográfica e o tratamento psicanalítico. Para que melhor compreendamos suas similaridades, proponho abordar a teoria do trauma na próxima seção, para depois relacioná-la às possibilidades aqui levantadas.

\section{Trauma, abjeção e assimilação}

A partir de minha leitura da teoria do trauma, e de discussões promovidas por um grupo de colegas da academia ${ }^{5}$, entendo que a urgência da escrita autobiográfica pode ter como uma de suas origens a necessidade que o autobiógrafo tem em assenhorear-se das experiências indesejáveis pelas quais passou, experiências estas que tenham lhe causado forte dor emocional, e que possam ter se configurado como traumáticas. Para que possamos entender tal pressuposto, faz-se necessária uma breve explicação de alguns aspectos da teoria freudiana do trauma.

Em “Além do Princípio do Prazer", Freud explica que aquilo que chama de "camada protetora contra estímulos" pode sofrer um rompimento, efetuado por uma experiência para qual o indivíduo não está preparado. Com esse rompimento, o aparelho psíquico fíca desprotegido, e passa a sofrer uma inundação de estímulos, o que desestabiliza sua economia energética. Para que o aparelho psíquico retorne a uma condição de estabilidade, é necessário que o mesmo capture e enlace tal afluxo de estímulos (FREUD, 2011, p. 153-154).

Nesse texto, Freud aborda a compulsão à repetição de certos padrões de comportamento, como também à repetição de sonhos desagradáveis, fatores estes que gerariam desprazer ao indivíduo. Freud se indaga se tal compulsão não seria uma tentativa do aparelho psíquico de retornar ao momento em que o escudo protetor fora rompido, para que o indivíduo pudesse reviver tal momento estando preparado para o choque que sofrera (FREUD, 2011, p. 155-156). Ele conclui que, ao seguir tal processo, o aparelho psíquico

\footnotetext{
${ }^{5}$ Me refiro aqui ao grupo formado pela Profa. Dra. Rosana Kohl Bines e pelos alunos, mestrandos e doutorandos, que cursaram a disciplina "A escrita de história e memória" no primeiro semestre de 2011. O curso foi oferecido pelo Programa de Pós-graduação em Letras, da PUC-Rio, sendo as aulas ministradas pela professora acima referida.
} 
opera buscando capturar e enlaçar tais estímulos desagradáveis, para que o mesmo volte a uma condição de estabilidade (FREUD, 2011, p. 156-157). Porém, nota-se que tal tentativa não é bem sucedida, visto que a repetição continua. Isso me leva a entender que a assimilação da experiência traumática, a que pretende o aparelho psíquico ao realizar o processo acima descrito, não acontece por si só.

Talvez o processo tenha de ser facilitado com estímulos exteriores, de forma consciente. Isso seria realizado através da psicanálise, obviamente, com ajuda do analista. Mas, outro fator que poderia auxiliar neste processo seria transformar a experiência desagradável em narrativa. Como exemplo, cito a motivação por trás da escrita autobiográfica de Elie Wiesel. Em “Por que eu escrevo?”, Wiesel argumenta que uma das razões que o leva a escrever é a busca pela compreensão dos eventos que experienciou ${ }^{6}$ (WIESEL, 1994, p. 25). Ligando tal asserção à lógica da teoria freudiana acima mencionada, creio que poderíamos ver a escrita autobiográfica como tentativa consciente de enlace e assimilação de vivências desagradáveis ${ }^{7}$. Através da escrita, o autobiógrafo efetua um processo de auto-análise, para então organizar os dados levantados em uma narrativa, buscando maior compreensão sobre sua existência.

Geoffrey H. Hartman aponta para tal possibilidade em seu texto "Holocausto, testemunho, arte e trauma”. Hartman aborda as narrativas testemunhais da Shoá, mas algumas de suas contribuições podem ser articuladas a outros exemplos das escritas-de-si, o que gera possibilidades fecundas. Além de demonstrar a importância do leitor em narrativas testemunhais, visto que o escritor busca por alguém que o compreenda, por uma comunidade afetiva (HARTMAN, 2000, p. 210-211), Hartman afirma que ao narrativizar uma experiência, o indivíduo pode assenhorear-se da mesma. Em suas palavras:

\begin{abstract}
As perturbações associadas com o trauma são, segundo Freud, tentativas do sistema de se preparar retrospectivamente para um choque que já ocorrera, de alcançá-lo e dominá-lo. A memória, e especialmente a memória usada na narração, não é simplesmente um nascer póstumo da experiência, uma formação secundária: ela possibilita $^{8}$ a experiência, permite que aquilo que chamamos de o real penetre na consciência e na apresentação das palavras, para tornar-se algo mais do que só o trauma seguido por um apagamento mental higiênico e, em última instância, ilusório. (HARTMAN, 2000, p. 222-223)
\end{abstract}

\footnotetext{
${ }^{6}$ Elie Wiesel é judeu que sobreviveu aos campos de concentração nazistas na segunda guerra mundial.

${ }^{7}$ Devo esta noção ao doutorando e colega Rogério Pacheco Jordão, a quem sou grato. O discente levantou tal hipótese quando da discussão de "Além do Princípio do Prazer", de Sigmund Freud, e de "A morte, o sexo, a mãe e o mal", de Maria Rita Kehl, textos pertencentes ao programa do curso referido anteriormente.

${ }^{8}$ Grifos do próprio autor.
} 
Em nota de rodapé relativa à citação acima transcrita (nota de número 36), Hartman diz que "[a]s convenções sociais ou literárias que a arte compartilha com o que é freqüentemente chamado de memória coletiva, também apresentam esse poder formal de tornar a experiência inteligível e de transmitir mesmo eventos sublimes e terríveis" (HARTMAN, 2000, p. 223). A escrita, portanto, é vista por Hartman como exercício que auxilia o indivíduo a processar e assimilar sua existência. Tal contribuição é de extrema importância para os estudos das escritas-de-si. Exemplos deste tipo de escrita poderiam ser concebidos, então, como tentativas por parte de seus autores de retornar a momentos cruciais de suas vidas, a fim de compreendê-los mais profundamente, e assenhorear-se dos mesmos ${ }^{9}$. Ao narrativizar sua própria experiência, o indivíduo olha para si mesmo de forma consciente e distanciada, e experiencia vivências passadas de uma posição em que esteja preparado para as assimilar.

Tal conclusão pode ser ligada a alguns pontos levantados por Maria Rita Kehl, em seu texto "A morte, o sexo, a mãe e o mal". Neste texto, a autora aborda a representabilidade/irrepresentabilidade de certos aspectos da realidade. Apesar de reconhecer que há um núcleo na realidade não passível de descrição, Kehl afirma que é nosso dever ampliar os limites do simbólico, a fim de invertermos a posição passiva que temos diante do real (KEHL, 2000, p. 138-139). A autora lida basicamente com experiências apassivadoras relacionadas a catástrofes, mas creio que possamos articular tais contribuições às escritas-de$s i$, especialmente quando lidamos com aspectos da vida de um indivíduo que são concebidos como indesejáveis pelo mesmo. Para Kehl, o ato de escrever ou falar sobre experiências traumáticas tem a potencialidade de trazê-las de volta à dimensão humana. Isso consistiria numa tentativa do indivíduo em exercer algum domínio sobre a experiência desagradável (KEHL, 2000, p. 145).

Se considerarmos as contribuições de Hartman e Kehl, acima esboçadas, e as articularmos às escritas-de-si, poderíamos dizer que a escrita de natureza autobiográfica pode ser vista, em alguns momentos, como uma tentativa de assimilar aquilo que o indivíduo não conseguiria reconhecer como parte integrante de seu eu, aquilo que Julia Kristeva chamaria de abjeto. Em “Approaching Abjection”, Kristeva explica que o abjeto é aquilo que se encontra

\footnotetext{
${ }^{9}$ Tal conclusão vai de encontro a algumas linhas teóricas nos estudos de literatura, em especial à obra de Maurice Blanchot, que defendia ser a literatura um espaço onde o autor e o mundo são suprimidos. Blanchot via a literatura como uma realidade fora da realidade do mundo e do autor, existente em si só (para maiores informações sobre tais ideias de Blanchot, se referir ao ensaio "A essência da literatura, segundo Blanchot", do professor Karl Erik Schøllhammer, disponibilizada na rede, na página "prosa online" do jornal O Globo). Fica claro, que não compartilho da visão de Blanchot neste aspecto.
} 
fora da relação sujeito/objeto, fora da ordem do simbólico, é um significado sem significante. Nas palavras de Kristeva: "toda abjeção é, na verdade, um reconhecimento da falta ${ }^{10}$ sobre a qual qualquer ser, sentido, linguagem ou desejo se fundamenta" (KRISTEVA, 1982, p. 5). Como Kristeva demonstra, a ideia de abjeção se manifesta de forma mais concreta quando nos deparamos com possibilidades ou concretudes indesejáveis inerentes a nossa existência, como a morte, por exemplo (KRISTEVA, 1982, p. 4). Ao nos deparar com um cadáver, somos levados a pensar em nossa própria morte, que é fato da existência, porém, fato que não queremos assimilar. Outra manifestação do abjeto consiste em nossos dejetos, fluidos corporais que nos geram nojo, mas que são por nós produzidos, portanto parte de nós. O abjeto seria aquilo que existe dentro de nós, que faz parte de nossa existência, mas que não queremos reconhecer como tal.

Em “As palavras, os corpos e as fronteiras do humano”, Nízia Villaça explica que ao ser confrontado com o abjeto, o "sujeito perde progressivamente seu pathos autoritário, sua referencialidade, estabilidade e controle sobre o objeto, assumindo a etimologia de subjectum, assujeitado" (VILLAÇA, 2008, p. 182). O abjeto nos causa tal estranhamento que somos levados a conceber sua experiência como traumática. Por ser aquilo em que nossa existência se fundamenta, como afirma Kristeva na citação acima transcrita, o abjeto poderia ser entendido como o trauma da existência, um trauma que carregamos por sermos quem somos. Como poderia o sujeito assimilar o abjeto? Como poderia o sujeito nomear o abjeto, dar-lhe um significante? Kristeva parece responder esta questão argumentando que é a literatura que o faz (KRISTEVA, 1982, p. 5). Aqui volto à ideia acima aventada de que a escrita pode nos ajudar a assimilar ou compreender dados indesejáveis sobre nossa experiência. Se o ato de narrativizar auxilia o indivíduo a retornar ao momento do trauma para revivê-lo de forma que possa compreendê-lo, talvez o mesmo aconteça em relação ao abjeto. Ao narrativizarmos aquilo que não gostaríamos de reconhecer como parte integrante de nosso eu, poderíamos assimilar nosso lado abjeto, ou seja, reconheceríamos tais partes como inerentes a nosso ser.

Isso é de extrema importância para as escritas-de-si, em especial para o romance autobiográfico. Já mencionei anteriormente, em consonância com Galle, que o romance autobiográfico dá ao escritor a possibilidade de apresentar um lado oculto de sua subjetividade, sem ter de assumir responsabilidade sobre o que é dito. A ficcionalização de suas experiências, portanto, lhe ofereceria as condições para que o escritor pudesse abordar seus traumas, suas vivências indesejáveis, seu lado abjeto, para que os processasse e, assim,

\footnotetext{
${ }^{10}$ Grifos da própria autora.
} 
os assimilasse. O protagonista de um romance autobiográfico poderia ser visto, então, como a concretização do lado abjeto do autor, ou melhor, como o dejeto de seu eu. Trazendo tais ideias em mente, proponho abordar a personagem Francis Xavier Enderby, como um dejeto autobiográfico de Anthony Burgess.

\section{Francis Xavier Enderby como dejeto autobiográfico de Anthony Burgess}

Quando escreveu Little Wilson and Big God, primeiro volume de sua autobiografia, Anthony Burgess se aproximava de seu septuagésimo aniversário. Entendendo não ter muito tempo de vida, o autor inicia sua autobiografia afirmando que era apropriado pensar na morte (BURGESS, 2002a, p. 4). O subtítulo do volume - Being the First Part of the Confessions of Anthony Burgess - aponta para a natureza confessional de seu livro. Quando penso na palavra confissão, dois significados vêm imediatamente à minha mente: o primeiro sendo ligado à esfera jurídica, que consiste em um ato em que o réu reconhece e declara ser verdadeiro o fato a ele imputado; o segundo significado se remete à esfera religiosa, que, segundo a tradição cristã católica, consistiria na declaração de pecados e posterior assunção de culpa pelos mesmos por parte de um pecador diante de um sacerdote, no intuito de se obter perdão. Diante do prospecto de seu fim, e por ter sido criado como católico, Anthony Burgess pode ter pensado em se confessar através de sua autobiografia, não necessariamente para obter perdão ou salvação, mas, talvez, para revisitar seu passado, e aceitá-lo como parte integrante de seu eu.

Algo semelhante pode ter acontecido quando o autor escreveu o romance Enderby por dentro. Ao fim de 1959, Anthony Burgess, que na época morava em Bornéu, trabalhando como professor pela coroa britânica, retornou à Inglaterra, a fim de realizar exames médicos, já que havia adoecido, tendo um colapso em sala de aula. Depois dos exames, seus médicos lhe deram um ano de vida, ao diagnosticarem um tumor cerebral ${ }^{11}$. Tal notícia levou Burgess a escrever compulsivamente, chegando a finalizar cinco romances em um só ano, e a iniciar um sexto. Enderby por dentro é escrito durante este famoso ano terminal. O fato de o autor se deparar com sua morte tão próxima, pode o ter levado a refletir sobre sua existência, retornar a seu passado, e se confrontar com aspectos de sua vida dos quais não se orgulhava. Não posso afirmar nada em relação à motivação por trás da escrita de Enderby por dentro, mas a ideia de que o texto seja um exercício confessional por parte de Burgess, no intuito de

\footnotetext{
${ }^{11}$ Os médicos estavam errados. Burgess viveu até o ano de 1993.
} 
apoderar-se de seu passado, ou seja, de assimilar-se a si próprio, me soa extremamente convidativa.

Além disso, se examinarmos os pontos de interseção entre o protagonista do romance e seu criador, a proposta acima referida tornar-se-á mais interessante ainda. O que me leva a enxergar Enderby como recontextualização de Anthony Burgess é aquilo que Philippe Gasparini (2004) chama de operadores de identificação ${ }^{12}$. Além da semelhança no tocante à atividade profissional das duas figuras, visto no fato de Enderby ser poeta e Burgess ser romancista, ambos compartilham a idade, que era próxima quando da escritura do romance. Outro operador é o local onde Burgess residia quando escreveu o título, que é o mesmo onde situa a residência de Enderby no universo ficcional, a cidade de Brighton, no sul da Inglaterra. Se pensarmos sobre o conteúdo da obra, encontraremos os operadores mais importantes em ação. Enderby por dentro lida basicamente com três temas: (1) a visão do que deve ser a arte na opinião de seu protagonista; (2) a dificuldade do mesmo em demonstrar afeto ou se relacionar em sociedade, devido à falta de relacionamentos afetuosos em sua criação, já que havia perdido sua mãe em sua primeira infância, e fora criado por uma madrasta por quem nutre absoluta aversão; (3) sua dificuldade em lidar com sua apostasia do catolicismo, fé que fora educado a seguir. Em "Why I am Eight Years Younger than Anthony Burgess", Gore Vidal faz uma resenha crítica sobre Little Wilson and Big God. Neste texto, Vidal identifica como sendo os três pontos principais da referida obra os seguintes: (1) a visão estética de Anthony Burgess; (2) a dificuldade que o romancista teve em se relacionar com outras pessoas por não demonstrar afeto facilmente, que Burgess entende se originar do fato de ter perdido sua mãe em sua primeira infância, e ter sido criado por uma madrasta por quem nutre grande aversão; (3) sua relação mal-resolvida com sua antiga fé, o catolicismo, da qual decidiu se desligar quando ainda jovem (VIDAL, 1990, p. 233-234). Outros operadores poderiam ser citados, até mesmo concretos, porém, a limitação de espaço do presente trabalho não me permite fazê-lo. Considero suficientes as evidências acima relatadas, para que possamos ler Enderby por dentro como romance autobiográfico.

Para prosseguir com minha proposta, exporei, brevemente, a história contada no romance, como também algumas passagens importantes. Enderby por dentro é dividido em três partes, que são subdivididas em capítulos. A primeira parte nos apresenta o protagonista

\footnotetext{
${ }^{12}$ Operadores de identificação são pontos de convergência entre romancista e personagem, que levam o leitor a enxergar o autor em personagens de seus romances. Logicamente, isto só pode ocorrer se o leitor conhece relatos sobre a vida do autor. Estes operadores consistem em experiências compartilhadas, meio sócio-cultural, profissões contíguas, aspirações, entre outros exemplos. Para mais informações sobre tais operadores se referir a GASPARINI, Philippe. Est-il je? Roman autobiographique et autoficcion. Paris: Seuil, 2004.
} 
Francis Xavier Enderby, um poeta, que, apesar de admirado e reconhecido, ainda não tem nenhum de seus poemas publicados em antologias. Enderby é um misantropo, que evita travar contato prolongado com outras pessoas, já que não deseja interferências em sua relação com a musa. Seus recursos financeiros derivam de uma herança deixada por sua madrasta, e são suficientes para que ele viva da maneira como lhe apraz. A personagem é um esteta, no sentido da mesma viver pela arte e para a arte. Enderby vive dentro de seu mundo linguístico, sem demonstrar muito interesse pelo mundo exterior.

Dada sua preocupação quase exclusiva com a arte, Enderby demonstra dificuldades com elementos práticos do dia-a-dia. Seu apartamento é sujo e desarrumado. Sua aparência um tanto desagradável, já que ele não tem bons hábitos de higiene pessoal. Sua banheira se tornou um arquivo para seus poemas em construção, que são geralmente escritos quando a personagem se assenta no vaso sanitário, para dar conta de suas necessidades fisiológicas. Ele não cuida bem de sua alimentação, o que o faz sofrer de uma constante dispepsia. Em vários momentos do romance somos confrontados com onomatopéias que simbolizam flatos ou eructações. Em suma, Enderby é uma figura nada cativante.

Muito do desinteresse da personagem pelo mundo deriva do relacionamento deveras negativo que teve com sua falecida madrasta. Este fator consiste em um dos vários operadores de identificação entre criador e criatura. Assim como Anthony Burgess, Enderby foi criado por uma madrasta por quem nutre um enorme sentimento de repulsa. No romance, a madrasta do protagonista é responsável por um ponto muito importante: sua apostasia do catolicismo.

Em alguns momentos do romance, Enderby demonstra sua ligação com a Igreja Católica Romana, e demonstra que sua apostasia teria sido dolorosa. Assim como Burgess que, apesar de apóstata, confessou em entrevista a Samuel Coale que nunca pode verdadeiramente deixar a Igreja Católica, já que, em suas próprias palavras, "ela é a única coisa que está lá", "não há nada mais" (COALE, 1981, p. 437) - Enderby tem uma relação contraditória com sua fé. Na passagem abaixo transcrita, quando Enderby pensa sobre sua obra e sobre como seria lido na posteridade, poderemos enxergar um pouco da relação contraditória da personagem com o catolicismo:

Já fraca no pai comerciante (...), a fé morrera no filho poeta, graças àquela madrasta. Há mais de vinte anos que era tarde demais para revisitá-la - retomar sua dignidade intelectual, sua teologia fria e coerente. Enderby havia se livrado dela, com lágrimas amargas, na adolescência, ajudado por Nietzsche, Tólstoi e Rousseau, e na tentativa de criar seus próprios mitos se tornara poeta. Não poderia mais retornar a ela, nem mesmo se quisesse tal coisa. Se o tentasse, teria de recorrer aos convertidos que escreviam romances de crime por achar que suas almas estavam perdidas, ou que, formando clubes exclusivos de convertidos egressos de Oxford e achando que tais agremiações eram a Igreja, não deixariam Enderby juntar-se a eles. Como sua 
apostasia era notória, Enderby seria classificado juntamente com diversos irlandeses amalucados. Assim, era melhor ser discreto em relação a sua fé ou agnosticismo (...); o único problema era que sua arte se recusava a ser discreta. (BURGESS, 1990, p. 59-60).

A arte da personagem, como a de seu criador, não deixa de revelar seu background religioso. Mas, ainda assim, tanto Burgess quanto sua criação Enderby são apóstatas. Como dito acima, a madrasta da personagem é apresentada como responsável por sua apostasia. Mas, além disso, tal figura odiada faz com que Enderby perca até seu interesse por mulheres, como demonstrado na passagem em que Enderby escreve o seguinte em um pedaço de papel higiênico: "[t]oda mulher é madrasta" (BURGESS, 1990, p. 60). Essa é uma das razões para que ele seja um solteirão convicto. Além de não desejar nenhum tipo de intromissão feminina em sua relação com a musa, o protagonista não consegue conceber nenhum indivíduo do sexo oposto como algo diferente da madrasta por quem sente tanta aversão.

Tal repulsa pelo sexo oposto é um dos pontos principais para o desenvolvimento da trama. Em certo momento, Enderby acidentalmente envia um poema amoroso para Vesta Bainbridge, a editora de uma revista feminina, ao invés de enviar uma reclamação sobre uma receita publicada em tal periódico. Após tal erro, Vesta o visita, e fica impressionada com seu talento artístico. Porém, a personagem também se impressiona com a vida insalubre que o protagonista leva, e acredita que isso se origine da falta do elemento feminino em sua vida. Como o leitor já deve ter previsto, os dois se casam, e Vesta assume como projeto, naquele momento, trazer Enderby de volta a uma vida social e saudável.

A segunda parte do romance narra a lua-de-mel do casal, e as consequências trazidas pelo casamento a Enderby. A primeira é a perda do poder do protagonista sobre suas decisões. Vesta passa a ditar o que ele fará, de que modo se vestirá, do que se alimentará, entre outras coisas relacionadas a sua rotina. A segunda consequência é a perda de contato com a musa. Enderby para de escrever. O protagonista entra num período de crise criativa, o que lhe traz enorme angústia.

Um dos principais momentos do romance ocorre justamente durante a referida luade-mel. Vesta Bainbridge é, assim como Enderby e como Anthony Burgess, uma católica não-praticante ${ }^{13}$. No entanto, a personagem demonstra a vontade de retornar ao seio de sua igreja, e deseja que seu novo esposo faça o mesmo. Devido a isso, ela planeja a viagem de

\footnotetext{
${ }^{13}$ Utilizo a tradução católico não-praticante para a versão original renegade catholic. Em sua autobiografia, Burgess utiliza o termo lapsed catholic. Entendo por "católico não-praticante" um individuo que foi batizado na Igreja Católica Romana, mas que não participa de ritos da Igreja Católica. Além disso, entendo que católicos não-praticantes são indivíduos que se designam como católicos, mas que conscientemente se opõe a determinadas regras ou preceitos da Igreja Católica Romana.
} 
lua-de-mel do casal a Roma, sede da Igreja Católica. Já em Roma, os dois conversam em um bar, falando sobre o império romano, que Enderby descreve como "[u]m grande queijo podre, cheio de vermes e verbos irregulares" (BURGESS, 1990, p. 178), ao que se segue o diálogo abaixo:

\begin{abstract}
Vesta ainda estava sorrindo, como Nossa Senhora na visão que Enderby experimentara naquele dia de calçadas escorregadias, viajando para Londres com um poema novo em gestação. -Você não ouve, não é? Você não me deixa dizer o que eu quero dizer.

-Paz romana, pois sim - rosnou Enderby.

-Eu não me referia a este império, e sim ao outro, o que surgiu nas catacumbas.

-Ah, meu Deus, essa não - murmurou Enderby.

(...) Vesta disse: -Você não tem a impressão de estar voltando pra casa? A volta do filho pródigo, sabe? Você resolveu se excluir do império e desde então se arrepende. Não adianta negar; isso os seus poemas revelam o tempo todo (BURGESS, 1990, p. 178).
\end{abstract}

Em outro momento Vesta decide que o casal deve realizar uma viagem de um dia apenas, aparentemente turística, para uma comuna perto de Roma. Durante a viagem, Enderby tira um cochilo, e, depois de despertar, o casal tem a seguinte conversa, iniciada pelo protagonista:

-Gozado nós dois sermos católicos relapsos ${ }^{14}$, não é? Você tem razão, dá um pouco a impressão de a gente estar voltando pra casa. Quer dizer, nós entendemos um país como esse melhor que os protestantes. As tradições daqui têm a ver conosco. (...) Mesmo que a gente não tenha mais fé - disse Enderby - a gente tende a achar a Inglaterra meio estranha, meio hostil. Quer dizer, quando a gente pensa nas igrejas que roubaram da gente. Se bem que por mim eles podem ficar com todas elas, mas é bom eles se lembrarem de vez em quando que na verdade elas são ainda nossas. (...) Vesta sorriu um sorriso um tanto azedo e disse: -Eu preferia que você não falasse dormindo. Pelo menos, não em público.

-É mesmo? O que foi que eu disse?

-Você disse "abaixo o papa" ou algo assim. Ainda bem que a maioria dos passageiros não fala inglês.

-Gozado - disse Enderby - Eu não estava nem pensando no papa. É muito curioso. Incrível as coisas que o subconsciente apronta, não é?

-Talvez fosse melhor você não dormir na próxima etapa da viagem - ordenou Vesta. -É a última.

-Mas, me diga uma coisa, ninguém falou no papa, nem nada parecido, não, falou? disse Enderby, intrigado. (BURGESS, 1990, p. 184)

Vesta contara apenas parte do plano para Enderby, dizendo que o casal visitaria um lago. Ao chegar no local, Enderby percebe que está perto do Lago Albano, onde fica situado o Castel Gandolfo, residência de veraneio do Papa. Enderby se encontra em meio a milhares de turistas, ou melhor, peregrinos, que viajam em busca do Papa. Quando o líder da Igreja Católica se apresenta, todos os peregrinos ficam entusiasmados e começam a bradá-lo, para

\footnotetext{
${ }^{14}$ A tradução de Paulo Henriques Britto apresenta o termo "católicos relapsos" para a versão original de renegade catholics.
} 
então se ajoelharem a fim de receber as bênçãos que procuram. Mas Enderby reage de forma diferente. Em meio a uma tremenda agonia, no que parece ser um ataque de pânico, ele tenta fugir do local, começa a chorar copiosamente, e chega perto de vomitar. Pisando em várias pessoas que rezavam ajoelhadas, ele consegue se retirar do pátio onde se encontrava. Abaixo transcrevo a passagem:

\footnotetext{
-Hurra, hurra, hurra! O papa, o papa, o papa!

-Meu Deus - soluçava Enderby -, me deixe ir embora, por favor. Não estou me sentindo bem, estou passando mal, preciso ir ao banheiro.

-A Igreja Militante está presente - disse Vesta, venenosa - e você quer ir ao banheiro.

-Quero, sim, quero, sim. - Enderby, os olhos marejados de lágrimas, estava agora atracado com um redolente espanhol, que não o deixava passar. A menina francesa continuava chorando, apontando para Enderby. De repente houve uma espécie de exórdio de prece, e todos começaram a se ajoelhar no chão. Enderby tornou-se uma espécie de professor irritado num mar de crianças miúdas. Ela também se ajoelhou. Vesta se ajoelhou; ajoelhou-se com todos os outros. -Levante-se! - gritou Enderby; e depois, como um sargento: -Levante-se daí, porra!

-De joelhos - ordenou-lhe Vesta, os olhos cheios de veneno verde mortífero. -De joelhos. Todo mundo está olhando pra você.

-Ah, meu Deus - chorava Enderby, rezando contra a corrente, e começou a tentar sair de novo, levantando as pernas como se caminhasse sobre melado. Pisou em joelhos, saias, até mesmo ombros, e foi amplamente xingado até mesmo por alguns que rezavam com sinceridade assustadora, os olhos enevoados de fervor. Tropeçando, xingando também, marchando num grotesco passo de ganso, apoiando episcopalmente a mão espalmada nas cabeças dos fiéis, atravessou como uma faca o imenso bolo de gente ajoelhada, e chegou, quase vomitando, cego de suor, no portão. Enquanto descia a ladeira, por entre vendedores sorridentes, murmurou baixinho: -Que idiotice minha, vir aqui. - Do alto do morro veio um imenso Amém. (BURGESS, 1990, p. 188-189)
}

A cena seguinte mostra o casal perdendo o ônibus que retornaria a Roma. Com isso, as personagens são forçadas a passar a noite numa pensão, onde, finalmente, se confrontam. Depois de uma tentativa de sexo frustrada, e de discutirem seu relacionamento, Enderby chega à conclusão de que Vesta se assemelha cada vez mais a sua madrasta, e propõe, então, o divórcio. Vesta, por sua vez, promete que tirará todo o dinheiro que Enderby tem, o que destruirá a independência financeira que ele obtivera, lhe negando a possibilidade de voltar a viver como fizera antes do casamento. A narrativa continua, chegando à terceira parte, quando Enderby não consegue mais lidar com sua crise criativa, o que o leva a uma mal-sucedida tentativa de suicídio. Depois disso, o protagonista é internado numa instituição mental, para tratar seu comportamento anti-social, que é visto pelos psiquiatras da instituição como infantil. Tais psiquiatras desejam transformar Enderby num adulto normal e produtivo para a sociedade.

Depois deste resumo do romance, o leitor pode estar indagando o que me levaria a considerar Enderby como dejeto autobiográfico de Anthony Burgess. Como já expus na 
introdução deste trabalho, Burgess via o ato de escrever como catarse. A liberdade trazida pela escrita ficcional, de que fala Galle, auxiliaria Burgess não apenas a se desvencilhar de seu lado abjeto, mas também a reconhecê-lo e aceitá-lo. Acredito ser por causa de tal fator que Burgess utilize a metáfora do excretar/escrever com Enderby. Através de seu alter-ego, Burgess se dá a liberdade de descrever suas experiências desagradáveis mais meticulosamente.

Não há como afirmar se a escrita de Enderby por dentro realmente ajudou Burgess a assimilar suas experiências desagradáveis. Mas a impressão que tenho, como leitor, é que, ao comparar a autobiografia do romancista à narrativa de Enderby por dentro, ou vice-versa, vejo com mais clareza os efeitos que certas experiências exerceram sobre ele. Por isso entendo que Enderby seja uma espécie de canal excretor sentimental para Anthony Burgess. Tal conclusão pode nos esclarecer a razão porque Burgess faz uso de escatologia na descrição de Enderby: o protagonista escreve sentado ao vaso porque é na realidade o canal pelo qual Burgess pode se purgar de si mesmo, simultaneamente excretando seu lado abjeto e reconhecendo um lado de sua subjetividade que não quisera anteriormente assumir.

Para que isso fique mais claro, abordarei rapidamente alguns elementos referentes à apostasia do escritor, elementos estes recontextualizados no romance em questão. Primeiramente, vou me ater ao nome do protagonista. Alguns especialistas da obra do romancista explicam que Enderby é uma região da Antártica, onde nada existe, onde não cresce vida. Portanto, a escolha deste nome para o protagonista aponta para o fato do mesmo ser uma personagem sem vida externa, já que vive somente em seu mundo de palavras.

Porém, nenhum dos especialistas que li até este momento atentou a uma outra possibilidade que desejo agora demonstrar. Burgess era também um linguista, e tinha o costume de inventar palavras ${ }^{15}$, como seus heróis William Shakespeare e James Joyce. Isso me leva a indagar se a palavra Enderby não seria uma espécie de jogo ou trocadilho. Levando isso em consideração, abordo tal palavra como sendo um vocábulo formado pelo processo de aglutinação, dos seguintes componentes: end $+e r+b y$. End significa finalizar na língua inglesa. Já -er é um sufixo da mesma língua que demonstra uma função ou profissão. Então, a junção de end + er poderia significar algo como "finalizador". O afixo by, neste caso, é pronunciado como o verbo to be no modo imperativo, que significa "seja" ou "esteja". Portanto, End $+e r+b y$ significaria algo como "seja o finalizador". Já o nome completo do

\footnotetext{
${ }^{15}$ Uma rápida leitura de qualquer página de seu mais famoso romance, A Laranja Mecânica, atesta a criatividade que Burgess possuía em inventar novos vocábulos.
} 
protagonista, que é Francis Xavier Enderby, nos levaria ao seguinte significado: "seja o finalizador de Francisco Xavier".

Em Little Wilson and Big God, Burgess nos relata que fora educado em escolas católicas, sendo o Xaverian College em Manchester o mais importante estabelecimento educacional por onde passou, antes da Universidade de Manchester. O romancista nos conta que sua educação em tal colégio, e em outras escolas católicas onde estudara, fez com que concebesse o catolicismo como uma religião extremamente dura e disciplinadora. Ele também nos conta que seu background católico originara-se não somente de sua formação escolar, mas também de sua madrasta. Assim como Enderby, Burgess via seu catolicismo como algo inseparável da madrasta que odiava. Isso poderia o levar a negar tal fé, já que a mesma o trazia lembranças tão desagradáveis. Porém, ser católico na Inglaterra tinha um significado mais profundo.

Burgess contou, em entrevista a Samuel Coale, que ser um católico na Inglaterra sempre lhe trouxe uma sensação de ser um estranho, um intruso, um outsider (COALE, 1981, p. 436). Sabe-se que depois da criação da Igreja Anglicana, os católicos da Inglaterra continuamente perderam muitos de seus direitos, que só foram devolvidos com o Ato de Emancipação, de 1829. Porém, o sentimento de não-pertencimento pareceu resistir entre os que professam tal fé. Ser membro da Igreja Católica na Inglaterra, certamente até a primeira metade do século XX, significava ser anti-establishment. Quando um grupo acredita em seus ideais, e sofre represálias por isso, normalmente adere mais fielmente a tais ideais, e luta pelo direito de demonstrá-los. A responsabilidade em professar a religião católica na Inglaterra, portanto, era grande.

Burgess nunca deixou de discutir e defender o catolicismo, até o fim de sua vida. No entanto, o romancista sempre teve problemas em aceitar tal fé completamente. O catolicismo estava intrinsecamente ligado a um poder disciplinador, assim como também à madrasta por quem Burgess nutria tanta repulsa. Sua relação com a fé católica, portanto, só poderia ser contraditória.

Acredito que essa contradição era muito forte para permitir que o escritor abdicasse totalmente de sua fé. Creio que isso também poderia lhe provocar uma dor sentimental profunda, que poderia se traduzir em vergonha. Seria justamente por isso que Burgess lança mão do romance autobiográfico, assim assumindo a subjetividade não-oficial que mencionei anteriormente. Através de Enderby, Burgess pode reconhecer seu lado obscuro, seu lado abjeto, pode aceitar-se a si mesmo, e sublimar sua relação com a Igreja Católica. Desta forma, concluo que Enderby funciona como um dispositivo para que Burgess assimile sua apostasia, 
e possa se desvencilhar da mesma. Francis Xavier Enderby, então, se torna o "finalizador de Francisco Xavier", o destruidor de seu passado católico, aquele que ajuda o romancista a sublimar a dor que sente por assumir o fim de tal relação. Enderby é ao mesmo tempo seu dejeto e seu redentor, seu lado abjeto e o cordeiro sacrificial através do qual o romancista pode expiar sua culpa por negar sua fé.

\section{Referências}

ARFUCH, Leonor. O espaço biográfico. Dilemas da subjetividade contemporânea. Rio de Janeiro: EdUERJ, 2010.

BURGESS, Anthony. Enderby por dentro. Trad. Paulo Henriques Britto. São Paulo: Companhia das Letras, 1990.

. Little Wilson and Big God: Being the First Part of the Confessions of Anthony Burgess. Londres: Vintage, 2002a.

You've Had Your Time: Being the Second Part of the Confessions of Anthony Burgess. Londres: Vintage, 2002b.

. Anthony Burgess Interviewed in Italy in 1974 about: A Clockwork Orange (and other

Subjects in General). Disponível em $<$ http://www.masterbibangers.net/ABC/index.php/online-texts-and-resources/textes-by-ab/49anthony-burgess-interviewed-in-italy-in1974-about-a-clockwork-orange.html> Acesso em: 29 maio 2011.

COALE, Samuel. An Interview with Anthony Burgess. Modern Fiction Studies, West Lafayette, v. 27, p. 429-452, out./nov./dez. 1981.

FREUD, Sigmund. Além do Princípio do Prazer. In: . Obras Psicológicas Completas de Sigmund Freud. Trad. Luiz Alberto Hanns. Rio de Janeiro: Imago, 2011. p. 122-197.

GALLE, Helmut. Elementos para uma nova abordagem da escritura autobiográfica. Revista Matraga, Rio de Janeiro, ano 13, n. 18, p. 64-91, jun. 2006.

GASPARINI, Philippe. Est-il je? Roman autobiographique et autoficcion. Paris: Seuil, 2004.

HARTMAN, Geoffrey H. Holocausto, testemunho, arte e trauma. In: NESTROVSKI, A.; SELIGMANN-SILVA, M. (org.). Catástrofe e Representação. São Paulo: Escuta, 2000. p. 207-235.

KEHL, Maria Rita, A morte, o sexo, a mãe e o mal. In: NESTROVSKI, A.; SELIGMANNSILVA, M. (org.). Catástrofe e Representação. São Paulo: Escuta, 2000. p. 137-148.

KRISTEVA, Julia. The Powers of Horror. New York: Columbia University Press, 1982. 
LEJEUNE, Philippe. O pacto autobiográfico. trad. Jovita Maria Gerheim Noronha, Maria Inês Coimbra Guedes. Belo Horizonte: Editora UFMG, 2008.

VIDAL, Gore. Why I am Eight Years Younger than Anthony Burgess. In: . At home: Essays 1982-1988. New York: Vintage Books, 1990. p. 231-240.

VILLAÇA, Nízia. As palavras, os corpos e as fronteiras do humano. In: DIAS, Â. M.; GLENADEL, P. (org.). Valores do Abjeto. Niterói: EdUFF, 2008. p. 181-196.

WIESEL, Elie. Por que eu escrevo?. In: VIEIRA, N. (org.). Construindo a imagem do judeu: algumas abordagens teóricas. Rio de Janeiro: Imago, 1994. p. 23-29.

[Recebido em junho de 2012 e aceito para publicação em dezembro de 2012]

\section{Autobiographical abjection: Francis Xavier Enderby as Anthony Burgess's residue}

Abstract: Considering the possibility of an intersection between texts belonging to the biographical space of a given individual (which is an idea firstly suggested by Lejeune and expanded by Arfuch), as well as the potentiality to build new facets or alternative subjectivities about such an individual, generated by such intersections, I propose to analyse the character Francis Xavier Enderby, protagonist of the autobiographical novel Inside Mr. Enderby, by the English writer Anthony Burgess, as his alternative subjectivity. Furthermore, I propose a reading based on questions related to the notion of abjection. I understand that the writing of autobiographical fiction can be an exercise through which a given writer tries to acknowledge sides of his/her subjectivity he/she would not like to assume as part of his/her "I", or an attempt to take control over disagreeable or traumatic experiences he/she has gone through, i.e. an attempt at dealing with his/her abject side. Following such a premise, I present comparisons between the self-image built by Anthony Burgess in his autobiography and the fictional character aforementioned.

Keywords: Biographical space. Autobiographical novel. Alternative subjectivities. Abjection.

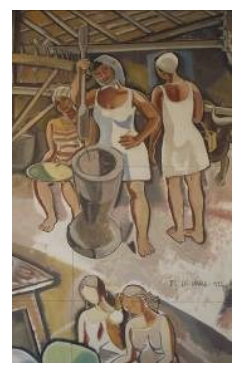

